\title{
Improvements in general health among the elderly: a factor in the rising incidence of hip fractures?
}

\author{
VILHJALMUR FINSEN \\ From the Department of Orthopaedic Surgery, Trondheim University Hospital, N-7006 Trondheim, Norway
}

SUMMARY Both hip fracture incidence and life expectancy are known to have increased during the last decades. Seventeen studies of hip fracture incidence from Great Britain and Scandinavia were collected from the literature. It was found that there was a good correlation for both men and women between the incidence of cervical but not trochanteric fractures in the 75-79 year age group and the mean life expectancy at 70 years of age at the time in the country concerned. The increased incidence is probably accounted for partly by the increased lifespan of the infirm. It is, however, suggested that increases in life expectancy among a majority of the elderly also entail better general health at any particular age, and that this may lead to a higher level of physical mobility which raises the risk of falls and fractures.

Many studies, mainly from Great Britain and Scandinavia, have shown an increase in the agespecific incidence of hip fractures over the last decades $^{1-10}$ and have pointed to the great burden this is placing on health services. ${ }^{1} 1112$

It is well known that there has also been a fairly constant increase in the life expectancy of the general population in the developed world during the last century. Moreover the life expectancy of the older segments of the population has increased significantly in most countries during the last decades. The present study was undertaken in order to determine whether there may be any connection between these two trends.

\section{Materials and methods}

All available studies on the incidence of hip fractures were collected from the literature. The incidence among 75-79 year old individuals was chosen as an indication of the general incidence because it is fairly high and the number of individuals of this age at risk is substantial. A number of studies gave the fracture incidence in 10 year increments or only graphically. Some authors responded to a request for more detailed incidence figures. In some cases it was possible to read the incidence fairly accurately from a graph or to construct a graph from the 10 year age group incidence figures and read the incidence from this. Approximately one third of the incidence figures were found in this way. Studies where this was impossible were excluded.

The average life expectancy at 70 years in the same country and period was found from statistical yearbooks of the relevant countries and from the United Nations Demographic Yearbook. The life expectancy at 70 years was chosen because this statistic is calculated on the basis of the death rate at the time of those of a higher age and thus indicates the general health of these older individuals. When studies covered more than one year, the life expectancy of the median year was used.

It did not prove possible to obtain appropriate life expectancy data for the USA, and American studies were therefore excluded. Because of the known racial differences in incidence, ${ }^{13}$ studies conducted on nonwhite populations were also excluded.

Theremaining 17studies, ${ }^{1-4}$ 8-10 12 14-22 which form the material of the present report, are all from the United Kingdom and Scandinavia. Some studies gave the incidence for various periods. No account was taken of the size of the studies.

\section{Results}

There was a highly significant correlation between remaining years of life and hip fracture incidence for both men ( $p<0.001$ : fig 1 , table) and women ( $\mathrm{p}<0.005$ : fig 2). This was due mainly to a strong correlation with cervical fracture incidence as no correlation was found with the incidence of trochanteric fractures.

A correlation was also found between hip fracture incidence and the year in which the fracture occurred for men $(p<0.01)$, but this did not reach statistical significance for women $(p<0 \cdot 1)$. 


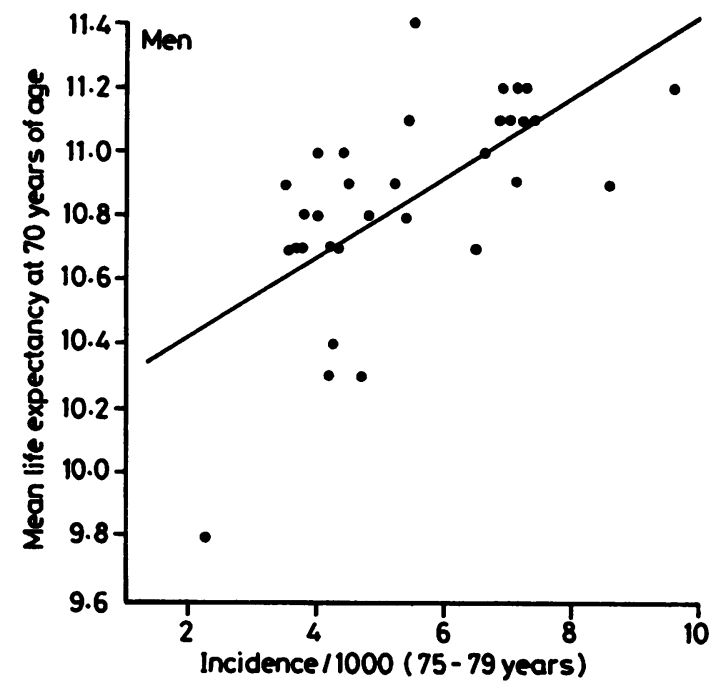

Fig 1 Relation between hip fracture incidence in 75-79 year old men and the average life expectancy at age 70.

Correlation of incidence of hip fractures (trochanteric and cervical) in the age group 75-79 years with average life expectancy at 70 years

\begin{tabular}{lllll}
\hline Fracture & & $n$ & $r$ & $p$ \\
\hline Hip & Men & 32 & 0.63 & $* * * *$ \\
& Women & 33 & 0.53 & $* * *$ \\
Cervical & Men & 26 & 0.49 & $*$ \\
& Women & 28 & 0.58 & $* * *$ \\
Trochanteric & Men & 21 & 0.33 & ns \\
& Women & 21 & 0.29 & ns \\
\hline
\end{tabular}

$\mathrm{n}=$ number of reports of fracture incidence; $\mathrm{r}=$ correlation coefficient; $\mathrm{ns}=\mathrm{not}$ significant; * $p<0.05 ; * * * p<0.005 ; * * * p<0.001$

\section{Discussion}

As both hip fracture incidence and life expectancy are increasing, it is not surprising in itself to find a correlation between them. What is noteworthy, however, is that this correlation is stronger than with year of fracture. It transcends national boundaries so that areas with lower life expectancy as a rule have a lower incidence of hip fractures. Attempts at interpreting findings such as the present must remain entirely speculative. They may be a matter of pure coincidence, but if they are not, it is possible that improvements in health care may be implicated.

There is circumstantial evidence that the older segments of the population not only have an increased life expectancy but also in most cases are enjoying better general health than before. Fries ${ }^{23} 24$ has pointed out that the average age of onset of chronic infirmity is increasing more rapidly than the increase in life expectancy. The period of severe disability before death is therefore being compressed, in addition to being postponed because of the increased average lifespan.

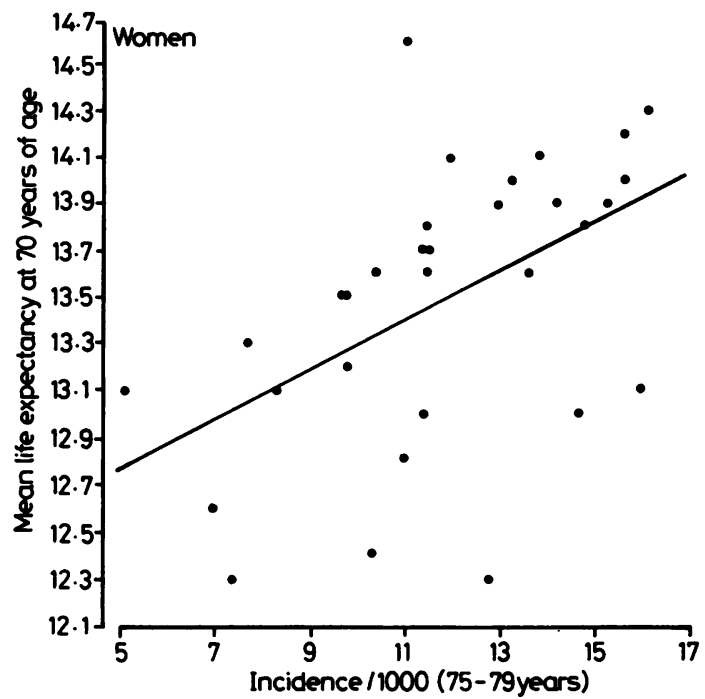

Fig 2 Relation between hip fracture incidence in 75-79 year old women and the average life expectancy at age 70.

Recent studies, however, have made it amply clear that hip fracture incidence is much higher among institutionalised patients than in the general population, ${ }^{2025}$ and that hip fracture patients on average are in poorer health than age-matched controls. ${ }^{2627}$ This was not so prevalent in the past, ${ }^{1428}$ and it may be that modern health care is prolonging the lives of the weak and infirm and thus causing an increase in the incidence of hip fractures.

There do, however, seem to be considerable differences between those who sustain trochanteric and those who sustain cervical hip fractures. Patients who have suffered one type of fracture usually have another fracture of the same type if they sustain a second hip fracture. ${ }^{29-31}$ Furthermore, trochanteric hip fracture patients are much more closely associated with physical debility than are those with cervical fractures. ${ }^{27} 3233$ Patients with cervical fractures, in contrast, are difficult to distinguish from age-matched controls, ${ }^{32}$ and mortality after such fractures returns to normal within a year of injury. ${ }^{34}$

Two main factors influence the occurrence of hip fractures: firstly, the strength of the skeleton and its ability to withstand trauma and, secondly, the trauma itself.

Traditionally focus has been centred on the weakening of the skeleton through osteoporosis. Studies based on radiological determination of bone 
mineral content of the hip, ${ }^{35-38}$ iliac crest biopsies, ${ }^{35} 3940$ and non-invasive evaluation of other parts of the skeleton ${ }^{4043}$ have in most cases concluded that hip fracture patients were particularly osteoporotic. Recent studies of bone mineral in the hip itself, however, ${ }^{44-46}$ have made it clear that the bone mineral content in the hip is the same or very similar in fracture patients and in controls. The evidence for an association with osteoporosis is somewhat stronger for trochanteric than for cervical fractures. ${ }^{35} 47$ In a recent extensive study, Eriksson and Widhe ${ }^{48}$ found reduced bone mineral in the hip of trochanteric but not cervical fracture patients. Workers in Finland have shown that those living in areas with a high content of fluoride in the drinking water have stronger bones than those who drink water with low fluoride content, but that there is no difference in the incidence of hip fractures in the two areas. ${ }^{4950}$ This may be a further indication that minor differences in bone strength may be less important in the aetiology of hip fractures than was previously thought.

Most hip fractures are demonstrably due to some degree of trauma, and the incidence of falls which lead to hospital admission among the elderly rises in a pattern almost exactly like that for hip fracture incidence. ${ }^{51}$ Prudham and Grimley Evans ${ }^{52}$ found that elderly women are twice as likely to sustain falls as men. Fallers were less mobile than non-fallers but also had an increased prevalence of episodic disability because of vertigo, faints or blackouts, transitory weakness and numbness, and double vision.

Pogrund and co-workers ${ }^{53}$ noted a significant increase in hip fracture incidence at national religious holidays and related this to increased physical activity among women at these times. Hip fracture patients have been found to be more likely to have suffered previous accidents and fractures than controls. ${ }^{54-56}$ Bastow $e a^{56}$ studied 744 elderly women with femoral fractures and found that two thirds of the healthiest 351 patients had sustained their fracture outdoors, indicating physical activity. Among the least healthy 138 patients the corresponding figure was only one quarter.

In spite of such reports implicating the role of falls due to physical activity in the aetiology of hip fractures, this has received relatively little attention. It is probable that some factors, such as an increased consumption of alcohol and psycholeptic and antihypertensive drugs, have increased the prevalence of falls. In addition, however, it seems reasonable to assume that increased general health leads to increased physical mobility and that this in itself increases the risk of falling.

In the present study we found that the close correlation between increases in life expectancy and hip fracture incidence was due to a correlation with cervical fracture incidence. No correlation was found with the incidence of trochanteric fractures. It is thus possible that the increase in hip fracture incidence is, paradoxically, due partly to better general health causing an increased incidence particularly of cervical fractures by lifting the elderly population up to a higher level of physical activity which increases the risk of slipping and tripping as well as falls because of episodic disability.

A possible hypothesis may thus be that the increasing incidence of hip fractures may in part be due to improvements in modern health care increasing to some extent the lifespan of a subset of the elderly population consisting of weak and debilitated individuals, leading to a rise particularly of trochanteric fracture incidence, and in part to a better control of chronic diseases leading to better health and well-being among most elderly people which in turn leads to increased physical activity, thus increasing the risk of falls and cervical fractures.

While it is true that correlation is no proof of causation, the association we have demonstrated between hip fracture incidence and life expectancy is stronger than with year of fracture, the only other demographic parameter known to correlate with hip fracture incidence. In addition, the present hypothesis fits with a number of the observations made over the years and offers a possible explanation for some of them.

\section{References}

${ }^{1}$ Fenton Lewis A. Fracture of the neck of the femur: Changing incidence. $\mathrm{Br}$ Med J 1981; 283: 1217-9.

2 Zetterberg C, Andersson GBJ. Fractures of the proximal end of the femur in Gøteborg, Sweden, 1940-1979. Acta Orthop Scand 1982; 53: 419-26.

${ }^{3}$ Frandsen PA, Kruse T. Hip fractures in the county of Funen, Denmark. Implications of demographic ageing and changes in incidence rates. Acta Orthop Scand 1983; 54: 681-6.

${ }^{4}$ Swanson AJG, Murdoch G. Fractured neck of femur. Pattern of incidence and implications. Acta Orthop Scand 1983; 54: 348-55.

${ }^{5}$ Wallace WA. The increasing incidence of fractures of the proximal femur: An orthopaedic epidemic. Lancet 1983; i: $1413-4$.

${ }^{6}$ Zetterberg C. Elmerson S, Andersson GBJ. Epidemiology of hip fractures in Gøteborg, Sweden. 1940-1983. Clin Orthop 1984; 191: 43-52.

${ }^{7}$ Johnell O, Nilsson B, Obrant K, Sernbo I. Age and sex patterns of hip fracture-changes in 30 years. Acta Orthop Scand 1984; 55: 290-2.

${ }^{8}$ Elabdien BSZ, Olerud S, Karlstrøm G, Smedby B. Rising incidence of hip fracture in Uppsala, 1965-1980. Acta Orthop Scand 1984; 55: 284-9.

${ }^{9}$ Finsen V, Benum P. Challenging incidence of hip fractures in rural and urban areas of central Norway. Clin Orthop 1987; 218: 104-11.

${ }^{10}$ Hedlund R, Lindgren U, Ahlbom A. Age and sex specific incidence rates of femoral neck and trochanteric fractures. An analysis based on 20358 fractures in Stockholm County 1972-1981. Clin Orthop (in press). 
${ }^{11}$ Luthje P. Fracture of the proximal femur in Finland in 1970 and in 1980. Acta Orthop Scand 1984; 55: 708.

12 Engesæeter LB, Søreide O. Consumption of hospital resources for hip fractures. Discharge rates for fracture in Norway. Acta Orthop Scand 1985; 56: 17-20.

${ }^{13}$ Bollet AJ, Engh G, Parson W. Epidemiology of osteoporosis. Sex and race incidence of hip fractures. Arch Intern Med 1965; 116: 191-4.

14 Alffram PA. An epidemiologic study of cervical and trochanteric fractures of the femur in an urban population. Acta Orthop Scand 1964; Suppl 65.

15 Knowelden J. Buhr AJ, Dunbar O. Incidence of fractures in persons over 35 years. A report to the M.R.C. working party on fractures in the elderly. Br J Prev Soc Med 1964; 18: 130-41.

${ }^{16}$ Gallanaugh SC, Martin A, Millard P. Regional survey of femoral neck fractures. Br Med J 1976; ii: 1496-7.

${ }^{17}$ Grimley Evans J, Prudham D, Wandless I. A prospective study of fractured proximal femur: Incidence and outcome. Publ Hlth Lond 1979; 93: 235-41.

${ }^{18}$ Baker MR. An investigation into secular trends in the incidence of femoral neck fracture using hospital activity analysis. Publ Hlth Lond 1980; 94: 368-74.

19 Jensen JS. Incidence of hip fractures. Acta Orthop Scand 1980; 51: 511-3.

${ }^{20}$ Hansson LI, Ceder L, Svensson K, Thorngren K-G. Incidence of fractures of the distal radius and proximal femur. Comparison of patients in a mental hospital and the general population. Acta Orthop Scand 1982; 53: 721-6.

${ }^{21}$ Walløe A, Andersson S, Herrlin K, Lidgren L. Incidence and stability of trochanteric femoral fractures. Acta Orthop Scand 1983; 54: 622-6.

22 Falch JA, Ilebekk A, Slungaard U. The epidemiology of fractures of the proximal femur in Norway. Acta Orthop Scand 1985; 56: 12-6.

${ }^{23}$ Fries JF. Aging, natural death, and the compression of morbidity. $N$ Engl J Med 1980; 303: 130-5.

${ }^{24}$ Fries JF. The compression of morbidity: Miscellaneous comments about a theme. Gerontologist 1984; 24: 354-9.

${ }^{25}$ Uden G, Nilsson B. Hip fracture frequent in hospital. Acta Orthop Scand 1986: 57: 428-30.

${ }^{26}$ Brocklehurst JC, Exton-Smith AN, Lempert Barber SM, Hunt LP, Palmer MK. Fracture of the femur in old age: $A$ two-centre study of associated clinical factors and the cause of the fall. Age Ageing 1978; 7: 7-15.

27 Johnell O, Sernbo I. Health and social status in patients with hip fractures and controls. Age Ageing 1986; 15: 285-91.

28 Stewart IM. Fractures of neck of femur. Incidence and implications. Br Med J 1955; i: 698-701.

${ }^{29}$ Stewart IM. Fracture of neck of femur. Survival and contralateral fracture. $\mathrm{Br} \mathrm{Med} J$ 1957; ii: 922-4.

30 Boston DA. Bilateral fractures of the femoral neck. Injury 1983; 14: 207-10.

${ }^{31}$ Finsen V, Benum P. The second hip fracture. Acta Orthop Scand 1986; 57: 431-3.

32 Lawton JO, Baker MR, Dickson RA. Femoral neck fractures - two populations. Lancet 1983; ii: 70-2.

${ }^{33}$ Elmerson S, Andersson GBJ, Bengtson M, Faxen E, Melstrøm D, Rundgren A, Zetterberg C. Difference in etiology of trochanteric and cervical fracture of the proximal femur. Acta Orthop Scand 1986; 57: 249.

34 Holmberg S, Conradi P, Kalen R, Thorngren K-G. Mortality after cervical hip fracture. Acta Orthop Scand 1986; 57: 8-11.

${ }^{35}$ Stevens J, Freeman PA, Nordin BEC, Barnett E. The incidence of osteoporisis in patients with femoral neck fracture. J Bone Joint Surg 1962; 44 B: 520-7.
${ }^{36}$ Vose GP, Lockwood RM. Femoral neck fracturing-Its relationship to radiographic bone density. J Gerontol 1965; 20: 300-5.

${ }^{37}$ Cook PJ, Exton-Smith AN, Brocklehurst JC, LempertBarber SM. Fractured femurs, Falls and bone disorders. $J$ $R$ Coll Phys Lond 1982; 6: 45-9.

38 Horsman A, Nordin BEC, Simpson M, Speed R. Cortical and trabecular bone status in elderly women with femoral neck fracture. Clin Orthop 1982; 166: 143-51.

39 Aaron JE, Anderson J, Stasiak L, Longton EB, Nordin BEC, Nicholson M. Frequency of osteomalacia and osteoporosis in fractures of the proximal femur. Lancet 1974; i: 229-33.

40 Evans RA, Ashwell JR, Dunstan CR. Lack of metabolic bone disease in patients with fracture of the femoral neck. Aust NZ J Med 1981; 11: 158-61.

41 Wootton R, Elsasser E, Freeman H, Green JR, Hesp R. Risk factors for fractured neck of femur in the elderly. Age Ageing 1982; 11: 160-8.

42 Johnell O. Nilsson BE. Bone mineral content in men with fractures of the upper end of the femur. Int Orthop (SICOT) 1984; 7: 229-31.

${ }^{43}$ Harma M, Karjalainen P, Hiokka V, Alhava E. Bone density in women with spinal and hip fractures. Acta Orthop Scand 1985; 56: 380-5.

44 Riggs BL, Wahner HW, Seeman E, et al. Changes in bone mineral density of the proximal femur and spine with aging. $J$ Clin Invest 1982; 70: 716-23.

45 Wicks M, Garrett R, Vernon-Roberts B, Fazzalani N. Absence of metabolic bone disease in the proximal femur in patients with fracture of the femoral neck. $J$ Bone Joint Surg 1982; 64 B: 319-22.

46 Bohr H, Schaadt O. Bone mineral content of femoral bone and the lumbar spine measured in women with fracture of the femoral neck by dual photon absorptiometry. Clin Orthop 1983; 179: 240-5.

47 Aitken JM. Relevance of osteoporosis in women with fracture of the femoral neck. $\mathrm{Br} M e d J$ 1984; 288: 597-601.

${ }^{48}$ Eriksson SAV, Widhe T. Femoral neck and trochanteric fractures in postmenopausal women-relationship between bone mineral density and type of fracture. Acta Orthop Scand (submitted).

49 Alahave EM, Olkkonen H, Kauranen P, Kari T. The effect of drinking water fluoridation on the fluoride content, strength and mineral density of human bone. Acta Orthop Scand 1980; 51: 413-20.

50 Arnala I, Alhava EM, Kivivuori R, Kauranen P. Hip fracture incidence not affected by fluoridation. Acta Orthop Scand 1986; 57: 344-5.

51 Lucht U. A prospective study of accidental falls and resulting injuries in the home among elderly people. Acta Sociomed Scand 1971; 2: 105-20.

52 Prudham D, Grimley Evans J. Factors associated with falls in the elderly: A community study. Age Ageing 1981; 10: 141-6.

53 Pogrund H, Makin M, Robin G, Menczel J, Steinberg R. The epidemiology of femoral neck fractures in Jerusalem. Clin Orthop 1977; 122: 141-6.

54 Johnell $O$. Nilsson BE. Hip fracture and accident disposition. Acta Orthop Scand 1985; 56: 302-4.

55 Finsen V, Benum P. Past fractures indicate increased risk of hip fracture. Acta Orthop Scand 1986; 57: 337-9.

${ }^{56}$ Bastow MD, Rawlings J, Allison SP. Undernutrition, hypothermia, and injury in elderly women with fractured femur: An injury response to altered metabolism? Lancet 1983; i: 143-8.

Accepted for publication January 1988 